\title{
Orangutans (Pongo pygmaeus) and bonobos (Pan paniscus) point to inform a human about the location of a tool
}

\author{
Felizitas Zimmermann • Franziska Zemke $\cdot$ Josep Call $\cdot$ \\ Juan Carlos Gómez
}

Received: 5 December 2007 / Revised: 5 September 2008 / Accepted: 25 September 2008 / Published online: 24 October 2008

(C) The Author(s) 2008. This article is published with open access at Springerlink.com

\begin{abstract}
Although pointing is not part of great apes' natural gestural repertoire, they can learn to point to food, in order to request it. To assess the flexibility with which they can use this gesture, one can vary the potential referent of the point. In two previous studies, three orangutans (two of them human-reared) have shown the ability to point to the location of a tool which a human experimenter needed in order to give them food. Here, we tested six orangutans and five bonobos using a set-up in which our subjects had to guide a human experimenter to the hiding place of a fork which was needed in order to retrieve a piece of food for the subject out of a vertical tube. We further examined the potential role of a competitive/deceptive context by varying the identity of the person responsible for hiding the tool. In addition, we implemented three different control conditions in which an object was hidden but it was not necessary to indicate its location to get the food. We found that the majority of subjects spontaneously guided the experimenter to the hiding place of the fork by pointing to it when it was necessary and they did so significantly less in control conditions. We did not find an effect of the person hiding the fork. Our results show that mother-reared orangutans and bonobos are able to point to inform a human about the location of an object that the human needs to procure food for the subject and that they can take into account whether it is relevant or not to do so.
\end{abstract}

Keywords Orangutans $\cdot$ Bonobos $\cdot$ Pointing $\cdot$ Flexibility . Theory of mind

F. Zimmermann $(\varangle) \cdot$ F. Zemke $\cdot$ J. Call

Max Planck Institute for Evolutionary Anthropology,

Deutscher Platz 6, 04103 Leipzig, Germany

e-mail: felizitas.zimmermann@eva.mpg.de

J. C. Gómez

University of St. Andrews, St. Andrews, Scotland, UK

\section{Introduction}

Index finger pointing (or some functional equivalent, e.g., lip pointing) to external entities is characteristic of human gestural communication. Human children begin to point by around their first birthday and especially in this young age when linguistic communication is restricted, pointing is one of the major means to communicate. In sharp contrast, there is little evidence so far that great apes point in the wild (e.g., Goodall 1986; Menzel 1973). In about 50 years of studying great apes in the wild there is only one documented instance of one ape pointing for another (Veà and Sabater-Pi 1998; see also Inoue-Nakamura and Matsuzawa 1997). The closest behavior chimpanzees do is to extend a hand to food held by others as a food begging gesture or as a request for help in agonistic interactions (de Waal and van Hooff 1981). But many individuals in captivity learn to point spontaneously (i.e., without explicit training) to food which is out of their reach to request it from a human caregiver, even when the food is not visible (e.g., Call and Tomasello 1994; Leavens et al. 2004; Woodruff and Premack 1979). There is even one study in which language-trained chimpanzees were reported to point for one another to indicate which "lexigrams" they wanted the other to press (Savage-Rumbaugh 1986). Additionally, for all four great ape species, especially for individuals that have been language-trained and reared in close contact with humans, there are anecdotal descriptions suggesting that they can point distally for things other than food including objects they want or locations they want to travel to (e.g., Miles 1990, Patterson 1978; Savage-Rumbaugh et al. 1986).

In the last decade, several studies have assessed pointing in various settings in a more systematic fashion. Leavens and colleagues have documented chimpanzees pointing 
intentionally to request food from an experimenter (Leavens and Hopkins 1998; Leavens et al. 1996, 2004). Menzel (1999) described the chimpanzee Panzee pointing to a variety of food locations to inform a naive human after delays of several hours. Russell et al. (2005) found that chimpanzees pointed to request from the experimenter a stick that the chimpanzee needed in order to access food. Gómez and Teixidor (1992) (see also Gómez 2004; Whiten 2000) and Call and Tomasello (1994) went a step further and asked whether orangutans are able to use pointing, not to request a tool for themselves, but to guide the human to a hidden tool that the human needed to access food for the ape. Two of the orangutans in these studies pointed spontaneously (and a third, after some additional training) to a location where the ape, but not the human, had previously seen the tool being hidden. They seemed to understand something about the informative value of the pointing gesture, at least what the human needed in the given situation and that pointing to it would draw her attention or action to the referent of the point. So at least these orangutans, all of whom had been raised by humans (at a nursery or in close contact with humans) and one that had also received language training, were able to use their pointing gestures flexibly, not only to request something, but also to direct a human to an entity that was instrumental in obtaining food. However, due to their contact with humans, it is unclear whether mother-reared orangutans would behave in the same way.

There is another important aspect of these results. Guiding the human to the hiding location could also have been motivated by an understanding that the human did not know where the fork was. A powerful variable that affects what humans tell or point out to others is what we think the other knows or ignores. Typically, humans tend to tell others (verbally or gesturally) things that they do not know and they assume are of interest to them, or that it is in our interest that they know, i.e., we inform them. Human communication is governed by this principle of "relevance" (Sperber and Wilson 1986). Currently we know that apes are able to point to request things and we know that apes, at least chimpanzees, are able to take into account the attentional state of partners in competitive (Bräuer et al. 2007; Hare et al. 2000, 2006; Melis et al. 2006) and communicative interactions (e.g., Gómez 1996; Kaminski et al. 2004; Leavens et al. 2004). Moreover, chimpanzees also take into account what others have and have not seen in the past in competitive situations (Hare et al. 2001). But it is unclear whether apes also take into account what someone else has or has not seen in their communicative attempts. Can they determine which aspects of a situation are "relevant" for communicative purposes?

Gómez and Teixidor (1992)(see Gómez 1998, 2004 for published reports of this study) addressed this question. The female orangutan Dona was presented with a situation in which she had to request food from a person by pointing to one of two locked boxes. To retrieve the food, the experimenter took the keys from a box where they were kept. In the critical trials, the keys were hidden by the "caterer" (i.e., the person who baited one of the boxes) in a different location before the experimenter entered the room. Dona started to guide the human to the hiding location in the second experimental trial, but only after the experimenter had gone for the keys to the usual location and was not able to find them. Although this shows that Dona recognized that the experimenter needed the keys, this behavior may not demonstrate an ability to understand the state of ignorance of the human because Dona pointed to the hiding location after the experimenter had searched for the keys in the wrong place. This means that Dona may have reacted to the experimenter's wrong behavior, not her knowledge state and therefore, it does not imply a theory of mind ability (Gómez 2004). After six sessions, Gómez and Teixidor changed the procedure and had a stranger hide the keys in the critical trials. From that point on, the subject pointed to both keys and food at the beginning of each trial, before the experimenter gave any sign of not being able to retrieve the keys. In Control trials when the experimenter had hidden the keys herself, Dona rarely pointed to the keys.

Gómez and Teixidor argued that the context of a stranger playing a trick on the experimenter may have activated a mind-reading (as opposed to behavior-reading) computation of the situation. There is evidence that the performance of human children in theory of mind tasks can be enhanced by presenting the story in a deceptive context (Núñez and Rivière 2007). Telling the children that the agent is trying to deceive the main character, instead of telling them that the change of location happened inadvertently, enhances the number of children able to predict correctly where the main character will go in search of the object. This is consistent with the finding that human adults do better in certain logical tasks if the task is posed in a deceptive context (Cosmides 1989). Furthermore, mind-reading skills have been recently found in chimpanzees when tested in competitive situations (Hare and Tomasello 2004).

The current study had three goals. First, to test if motherreared orangutans, just like human-reared orangutans, can also point to inform a human about the location of an object that the human needs to procure food for the subject. This is important because there have been some indications that the gestural communication of enculturated apes may be particularly sophisticated (Call and Tomasello 1996). Second, to assess the performance of another ape species, bonobos, in this task. These data are particularly important, given that very little is known about bonobo pointing behavior, practically nothing if one excludes the data from language-trained bonobos. Third, to investigate whether orangutans and bonobos take into account what a human 
has or has not seen when they inform the human about the location of hidden objects.

We adopted the procedure of Gómez and Teixidor which has also been successfully adapted for use with dogs, a chimpanzee and human children (Virányi et al. 2006; Whiten 2000). More specifically, we used the locked boxes/ hidden key procedure, and developed a new one in which a human had to use a fork to retrieve a piece of food for the subject. In experimental trials, the tool was hidden in an unusual location in the presence of the animal but not of the human experimenter. To assist the human in reaching the food, it was necessary for the subject to guide her to the hiding location by pointing to it. In the Control trials, an unnecessary object was hidden, or the helper witnessed the re-location of the tool (and the ape saw this) or the helper hid the fork herself and therefore it was not necessary to point to the tool location. This allowed us to investigate whether apes would point indiscriminately regardless of the object that was hidden or the amount of information that the helper possessed about the location of the tool. Finally, we also examined the potential role of a competitive/deceptive context by varying the identity of the person responsible for the hiding of the tool, the familiar baiter versus an unexpected stranger.

\section{Methods}

\section{Subjects}

Six orangutans (Pongo pygmaeus) and five bonobos (Pan paniscus) participated in this experiment (Table 1). There were seven females and four males ranging in age from 6 to 31 years. All subjects were born in captivity. Three bonobos were nursery-reared, whereas all other subjects were mother-reared. All subjects were housed at the Wolfgang Köhler Primate Research Center in the Leipzig Zoo
(Germany), where they lived with conspecifics in social groups, with access to indoor and outdoor areas. Subjects were fed according to their normal daily routine, that is, four times a day on a diet of fruit, vegetables, cereals and monkey chow. Water was available ad libitum, and subjects were not deprived of food during the testing period.

Subjects were tested individually in a familiar indoor testing room and could stop participating at any time. In some sessions, another group member was present during testing, but was kept in a separate compartment of the testing room, as sometimes individuals refused to leave the testing room. Subjects had participated previously or were concurrently participating in other studies including studies that required pointing to a food-baited container (e.g., object-choice tasks). So they were all used to pointing to objects to indicate a choice and request them. Two orangutans (Toba and Walter) served as subjects in the pilot study in which we used a slightly different procedure from that of the main study. The differences between the two procedures are noted below.

\section{Materials}

The testing room was divided into an ape area and a human area by a set of transparent Plexiglas panels and mesh windows (Fig. 1). On the experimenter's side, it was possible to fix four platforms $(80 \mathrm{~cm} \times 40 \mathrm{~cm})$ perpendicular to either a Plexiglas or a mesh panel. At the bottom of the Plexiglas panel were three holes forming a straight line separated by $25 \mathrm{~cm}$ from center to center.

On one of the platforms, we mounted two vertical opaque PVC tubes ( $5 \mathrm{~cm}$ in diameter $\times 22 \mathrm{~cm}$ high) side by side on a PVC board $(66 \mathrm{~cm} \times 25 \mathrm{~cm})$. We used the three remaining platforms to create six hiding locations (two per platform) by placing six easily distinguishable covers (a rectangular yellow plastic box, a piece of paper, a piece of jute, the cover of a shoe box, some straw and a piece of
Table 1 Species, age, sex, rearing history, place of birth and experiment in which each subject participated

Exp main experiment, pilot pilot study

\begin{tabular}{llcllll}
\hline Subject & Species & $\begin{array}{c}\text { Age at begin } \\
\text { of study (years) }\end{array}$ & Sex & Rearing history & Place of birth & $\begin{array}{l}\text { Participation } \\
\text { in experiment }\end{array}$ \\
\hline Joey & Bonobo & 22 & Male & Human-reared & Captivity & Exp \\
Kuno & Bonobo & 8 & Male & Human-reared & Captivity & Exp \\
Limbuko & Bonobo & 9 & Male & Human-reared & Captivity & Exp \\
Ulindi & Bonobo & 11 & Female & Mother-reared & Captivity & Exp \\
Yasa & Bonobo & 8 & Female & Mother-reared & Captivity & Exp \\
Dokana & Orangutan & 15 & Female & Mother-reared & Captivity & Exp \\
Dunja & Orangutan & 31 & Female & Mother-reared & Captivity & Exp \\
Padana & Orangutan & 6 & Female & Mother-reared & Captivity & Exp \\
Pini & Orangutan & 16 & Female & Mother-reared & Captivity & Exp \\
Toba & Orangutan & 10 & Female & Mother-reared & Captivity & Pilot \\
Walter & Orangutan & 15 & Male & Mother-reared & Captivity & Pilot \\
\hline
\end{tabular}


Fig. 1 Experimental setup in the main study

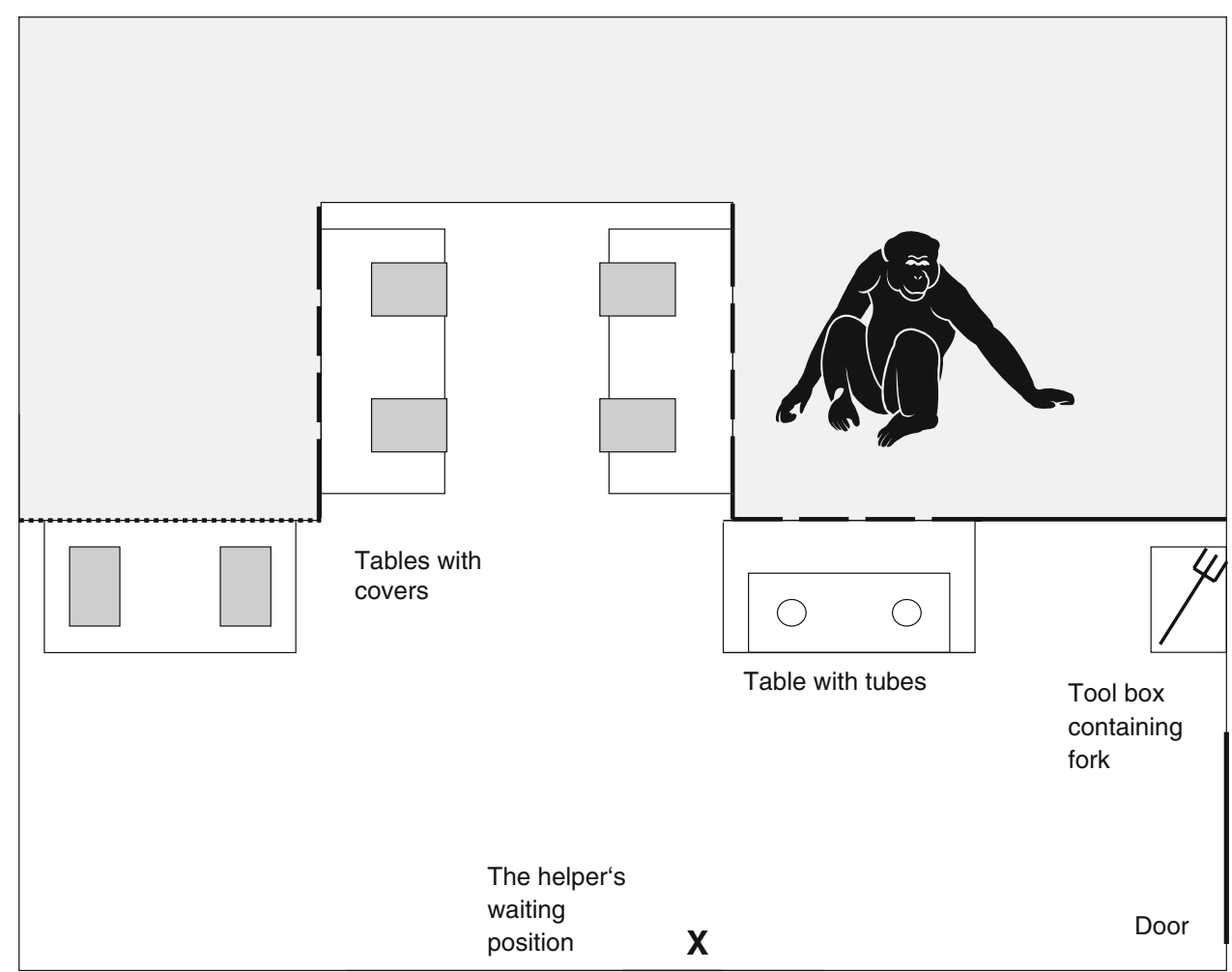

gray cloth) of roughly the same size $(18 \mathrm{~cm} \times 27 \mathrm{~cm}$ approximately). There were two covers on each platform placed on opposite sides of the platform so that subjects could point unambiguously to each of them by sticking a finger through one of the outer holes in the panel or through the mesh behind the cover, respectively. Each cover was always presented at the same location. A box with a lid $(21.5 \mathrm{~cm} \times 19.5 \mathrm{~cm} \times 6.5 \mathrm{~cm})$, placed on a stool on the right side of the tubes, served to keep a $25-\mathrm{cm}$ fondue-fork that the experimenter needed to retrieve the rewards from inside the tubes. The box was usually kept closed, so the fork could not be seen during trials unless the experimenter opened the lid.

The set-up and materials for the two pilot subjects reproduced the original "locked box/hidden key" scenario of Gómez and Teixidor (1992). Walter and Toba began their test with two lockable boxes (usual cash boxes) instead of tubes. The experimenter needed a key, which was kept in the tool box, to unlock the box instead of a fork. Furthermore, the covers were placed on the ground and later for some trials on two wooden tables. Later on we introduced the tubes/fork task whose logical structure was identical to the box/key task, but it represented an improvement in the set-up because the fork was directly connected to the food when retrieving it, and the keys (unlike the fork) were very small. As our subjects were used to indicating their choices by pointing to objects through the holes in the panels (not on the floor), we presented the covers on platforms in front of the panels in the main study. Pointing to the floor also made it harder for the experimenter to recognize the referent of the ape's point. Walter and Toba changed to the tubes and fork version after session 6 and 18, respectively. For the sake of simplicity, we will refer to the "fork" even in trials in which a key was used.

Procedure

Subjects received one daily session consisting of eight trials. There were four different kinds of trials: Exposure trials, Test trials, Show fork trials and Control trials. There were three phases: Familiarization, Testing and Control. Depending on the phase, a session comprised a different number of the different kinds of trials but always a total of eight trials. Table 2 presents an overview of the different phases and trials.

\section{Familiarization phase}

This phase served to familiarize the subjects with the procedure. Prior to the start of the first sessions, one experimenter (the helper) showed the ape how the grapes could be picked with the fork and that she could reach the inside of the tubes only with the fork and not with her hand. Additionally, the helper took the fork out of its box and showed it to another experimenter (the baiter) and to the subject and put it back into the box.

Initially, the orangutans seemed reluctant to point to the tubes to indicate the location of the food. It appeared that 
Table 2 Overview of the different phases of the study: number of daily sessions, number of different types of trials per session and description of the different types of trials for each phase of the study

\begin{tabular}{|c|c|c|c|}
\hline Phase & \# of daily sessions & $\begin{array}{l}\text { \# of trial-types } \\
\text { per session }\end{array}$ & Description of trial-types \\
\hline Familiarization & $\begin{array}{l}\text { Pilot Walter: } 2 \text { sessions, Toba: } 1 \text { session } \\
\text { Main study Variable until subject } \\
\text { reached } 80 \% \text { correct }\end{array}$ & 8 Exposure & $\begin{array}{l}\text { Fork successfully used } \\
\text { to retrieve grape }\end{array}$ \\
\hline Testing & $\begin{array}{l}\text { Variable until subject reached criterion to move } \\
\text { to the Control phase, divided into } 12 \text {-session } \\
\text { blocks of Baiter/Stranger hiding the fork }\end{array}$ & $\begin{array}{l}6 \text { Exposure } \\
1 \text { Show fork } \\
1 \text { Test }\end{array}$ & $\begin{array}{l}\text { Attention drawn to fork } \\
\text { Fork hidden }\end{array}$ \\
\hline \multirow[t]{2}{*}{ Control } & $\begin{array}{l}15 \text { Sessions (administered in } 3 \text { blocks } \\
\text { of } 5 \text { sessions with each type of control) }\end{array}$ & $\begin{array}{l}5 \text { Exposure } \\
1 \text { Show fork } \\
1 \text { Test }\end{array}$ & \\
\hline & & 1 Control & $\begin{array}{l}\text { Three different situations in which } \\
\text { something was hidden but pointing } \\
\text { to the hiding place was not needed }\end{array}$ \\
\hline
\end{tabular}

The Familiarization phase served to get the subjects used to pointing to the tubes; fork used by helper to retrieve grape. The Testing phase assessed whether subjects would indicate a re-location of the fork; fork hidden in one of the eight trials. The Control phase tested whether subjects would still indicate the hiding place when there was no need to do so; irrelevant object hidden or helper knew about the whereabouts of the fork

they waited for the experimenter to approach or push the platform towards them, a procedure commonly used in the object-choice tasks that they had received as part of previous studies. To remedy this situation, they received a stepwise training in which the helper waited in three different positions, moving further and further away from the subject's cage. Subjects needed between 13 and 19 training sessions until they reliably pointed to the baited tube even when the helper waited in her predetermined position. The two orangutans in the pilot study did not require this training because the helper always stood behind the platform with the tubes and subjects pointed right away.

During the Familiarization phase, subjects received eight Exposure trials per session in which the baiter entered the testing room, dropped a reward (usually a grape) in one of the tubes and left. About 20-30 s later, the helper entered the testing room and positioned herself on a designated location between the tubes and the covers, 80-140 cm from the subject's cage (Fig. 1). Due to the different sizes of the orangutan and bonobo testing rooms, the experimenter was closer to the bonobos than to the orangutans. For the two pilot subjects, the helper went directly to the platform with the tubes until session 24 . We chose the more neutral location in the main procedure to prevent introducing a bias for pointing to the baited tube instead of pointing to the hiding place. When the subject pointed to one of the tubes, the helper went to the platform, kneeled down, put her hand on the indicated tube and asked "Diese hier möchtest du?" ("This is the one you want?"). If the ape did not correct her choice, she took the fork out of the tool box. We introduced this short delay to give subjects the chance to point to the hiding place after pointing to the baited tube, but before the helper had looked for the fork in the tool box. We introduced the delay in session 29 of Walter and Toba and maintained it for the main study.

If the subject's choice was correct, the helper used the fork to retrieve the grape and handed the grape to the subject. If the choice was incorrect, the helper showed the subject that there was no grape inside the tube by poking on the bottom of the tube and showing her the empty fork and the subject was allowed to make a second choice. If the subject was not able to indicate the baited tube within $2 \mathrm{~min}$, the helper left the room and the baiter removed the food in the beginning of the next trial. The position of the grape (left vs. right) was randomly determined with two constraints: not to be hidden on the same side in more than three consecutive trials, and to appear maximally once more on one side than on the other overall during one session. Once subjects pointed to the correct tube in at least $80 \%$ of the trials in two consecutive sessions, the Testing phase started. Toba and Walter (the two pilot subjects) began the Testing phase after one and two Familiarization sessions, respectively.

\section{Testing phase}

This phase assessed whether subjects would point to the fork, which had been moved from its original location, which the helper needed to retrieve the food. A session consisted of six Exposure trials, one Test trial (in which the fork was hidden) and one Show fork trial. The order of the Test trial and Show fork trial in a session was randomly determined. The helper was unaware of the type of trial that was in progress, the location of the food in the tubes and the location of the fork.

Test trials were identical to Exposure trials except in that the baiter hid the fork under one of the six covers after baiting 
the tube (Baiter hides) or an unfamiliar third person (the stranger) entered the room after the baiter had left the room and hid the fork (Stranger hides). To emphasize their deceptive intent, strangers behaved in a sneaky fashion while hiding the fork (e.g., looking around as if checking whether someone can see her). Each subject received several 12-session blocks with either the baiter or the stranger hiding the fork, with the order of presentation counterbalanced across subjects. The two pilot subjects received stranger and baiter blocks of flexible length. About 10-25 s after the stranger/baiter had left the room, the helper came in. If the subject pointed to a tube, she behaved exactly like in Exposure trials. When she opened the tool box and noticed that the fork was not inside, she showed the subject that the box was empty by holding it upside down and demonstrated that she could not reach the grape by trying to reach into the tube with her hand. If then the subject pointed to a cover, the helper touched it asking "Dieses hier möchtest du?" ("This is the one you want?") and lifted it if the subject did not correct her choice. If it was the correct cover (i.e., the actual hiding place of the fork), she took out the fork and used it to retrieve the food. If it was an incorrect one, she showed the subject that the place was empty, and the subject could guide her to another cover. If the subject was not able to indicate the correct hiding location within $2 \mathrm{~min}$, the helper left the room and the baiter or the stranger came back, retrieved the fork, removed the food and put the fork back into the tool box. If the subject pointed to a cover before pointing to a tube, the helper first retrieved the fork and then returned to the tubes waiting for the subject to indicate the baited one. Trials in the pilot study did not have a predetermined length. For purposes of comparability with the non-pilot subjects, we did not score the subject's behavior after $2 \mathrm{~min}$ if the helper stayed in the testing room for longer.

Show fork trials were identical to Exposure trials except that, after the baiter had baited one of the tubes, she took the fork out of the tool box, showed it to the subject and put it back into the tool box. These Show fork trials served to have the subject's attention drawn to the fork in one trial like in Test trials but with no reason to point to its location. As soon as the subject reached a criterion of pointing to the hiding location of the fork before the helper started looking for the fork in the tool box, in three consecutive sessions or in four sessions out of five, the Control phase started. If subjects did not reach this criterion in 36 Testing sessions they were advanced to the Control phase anyway.

\section{Control phase}

This phase tested whether subjects would point to the fork after the helper had either witnessed its change of location or had moved the fork herself, and whether they would point to other hidden objects that the helper did not need to retrieve the food. The Control phase comprised 15 sessions. A session in this phase consisted of five Exposure trials, one Test trial, one Show fork trial, and one of three different types of Control trials.

In the Straw control, the baiter hid a piece of straw (about $23 \mathrm{~cm} \times 6 \mathrm{~cm}$ ). This controlled for the possibility that the subjects were pointing in response to the act of hiding per se. Subjects were not expected to point if they understood that it was the fork that the helper needed. In the Helper hiding control, the helper hid the fork herself at the end of the preceding trial, while in the Helper witness control, the helper was present and watched how the baiter hid the fork. So in both these controls, subjects did not need to guide the helper to the hiding location if they understood that the helper in these trials knew where the fork was hidden. Each of the three different controls was administered in a block of five consecutive sessions, with each subject receiving the three controls in a different order.

A difference in the procedure of the Helper hiding control between orangutans an bonobos should be noted. For the orangutans the helper hid the fork, left the room, then the baiter baited the tube and after she had left, the helper came back. In contrast, for the bonobos the helper entered after the baiter had baited the tube, left and came back again after a few seconds. We introduced this change for the bonobos because the orangutans may have been less likely to point in Control trials because they tended to stay close to the location where something had been hidden last. In this way, we made sure that the bonobos were as much focused on the hidden fork in Control as in Test trials as the sequence was exactly the same in both conditions.

Data scoring and analysis

Data were based on live coding and video coding by the helper (FZi for the orangutans; FZe for the bonobos). The response period for indicating the location of the fork started when the helper opened the door to the testing room and ended as soon as the helper had found the fork or after $2 \mathrm{~min}$ (although $2 \mathrm{~min}$ were allowed, usually the first response occurred early, within the first $10-20 \mathrm{~s}$ of the trial). For this time span, the helper scored to which hiding location the subjects pointed and whether they pointed to the tool box. "Points" were defined as inserting a finger through one of the outer Plexiglas holes or through the mesh so that it protruded in the direction of one of the mentioned objects. The coder also noted whether the subject pointed to the hiding place before the helper had started looking for the fork (i.e., before she had opened the tool box). This was important to determine whether subjects were able to anticipate the experimenter's lack of knowledge in those trials in which the fork had been moved from 
its original location. During the Testing phase, sessions were canceled if the subject did not point to the tubes in three consecutive trials. This happened in two sessions for Walter. One session of Padana was excluded due to experimenter error (a wrong Control trial, Giver hides instead of Straw control was administered in session 46).

For reliability purposes, the two helpers served as second coder for each other. FZi coded $20 \%$ of the bonobo trials and FZe coded $20 \%$ of the orangutan trials. Cohen's Kappa for the orangutans was 0.98 for points to covers, 1.00 for correct versus incorrect points, 1.00 for order of pointing (i.e., points to covers before or after the helper opened the tool box) and 0.66 for points to the tool box. For the bonobos, Cohen's Kappa was 0.98 for points to covers, 1.00 for correct versus incorrect points, 1.00 for order of pointing and 0.77 for points to the tool box. Reliabilities for points to the tool box were lower as it was very hard to see on the video when apes pointed to the tool box.

We compared the percentage of points to the tool box and covers across the different types of trials and how they changed over time. Since subjects advanced phases contingent upon reaching predetermined criteria (and different subjects progressed at different speeds), we selected the first 30 sessions with Test trials to conduct our comparisons over time. We analyzed subjects' pointing accuracy to hiding locations and whether they pointed to the food or the fork first (both for Test trials). We used two-tailed nonparametric statistics for all analyses.

\section{Results}

Familiarization phase

The nine subjects of the main study (the pilot subjects are excluded from this analysis because the experimenter decided when they advanced to the Testing phase) needed a median of 13 Familiarization sessions (range: $2-19 ; N=9$; see Table 3 for details) before advancing to the next phase.

\section{Testing phase}

In the Testing phase, two bonobos (Joey and Ulindi) did not point to a cover in 36 sessions and were therefore excluded from all subsequent analyses. The two pilot subjects are included in all the following analyses leading to a total of nine subjects.

Figure 2a presents the percentage of trials in which the subjects pointed to the covers (irrespective of whether it was the actual hiding place or not) in each type of trial of the Testing phase over time. Overall there were significant differences between trial types (Friedman test $=14.82, d f=2$, $N=9, P=0.001$; Test trials: median $=93.6$, inter-quartile range $=79.7-97.6$; Show fork trials: median $=0$, interquartile range $=0-2.8$; Exposure trials: $\operatorname{median}=0.91$, inter-quartile range $=0.21-1.78$ ). Pairwise comparisons revealed that apes pointed significantly more often to a cover in the Test trials than the other two types of trials (Wilcoxon test: $z=2.67, N=9, P=0.008$ in both cases). In contrast, there were no significant differences between the Show fork and Exposure trials (Wilcoxon test: $z=0.34$, $N=9, P=0.74)$.

We examined when subjects started to indicate a cover in Test trials (i.e., when the fork was hidden). Subjects started to point to the covers within two sessions as a median (range: 1-10). Four subjects (two orangutans and two bonobos) pointed in their first Test trial and two subjects (two orangutans) pointed in their second Test trial (Table 3). Walter who was the last subject to start pointing (in his tenth Testing session) had started to lead the helper to the hiding location of the fork already in his eighth Testing session by positioning himself close to the respective cover and staring at it (a behavior that was not considered in the analyses). There was no significant difference in the onset of pointing between the two species (Mann-Whitney Test: $Z=0.81, N=9, P=0.42$; Bonobos $(N=3)$ : median $=1$, inter-quartile range $=1-3$; Orangutans $(N=6)$ : median $=2$, inter-quartile range $=1.00$ $6.25)$.

Figure $2 b$ presents the percentage of trials in which the subjects pointed to the tool box for each trial type of the Testing phase over time. Overall, there were no significant differences between trial types (Friedman test $=1.86$, $d f=2, N=9, P=0.39$; Test trials: median $=2.4$, interquartile range $=0-8.2$; Show fork trials: median $=0$, interquartile range $=0-23.8$; Exposure trials: median $=0.85$, inter-quartile range $=0.2-15.3$ ). Moreover, there were no significant differences in the onset of pointing between trial types (Friedman test $=4.20, d f=2, P=0.12$; Test trials: median $=12$; Show fork trials: median $=27$; Exposure trials: median $=5$ ).

Figure 3 presents the accuracy of pointing to the hiding place in Test trials. Subjects pointed directly to the correct cover (i.e., the hiding place of the fork) in $60.9 \%$ of trials, which is significantly above chance levels (Wilcoxon test against the expected 16.7\%: $z=2.67$, $P=0.008$ ). Adding correct direct points and correct points after switching (i.e., pointing to the actual hiding place of the fork after having pointed to an empty cover first) accounted for $73.7 \%$ of the trials. There were no significant differences between the species with regard to correct pointing and correct pointing after switching (Mann-Whitney Test: $Z=1.9, N_{1}=3, N_{2}=6, P=0.20$ in both cases).

Next we analyzed whether subjects were more likely to point to a cover before or after the helper had looked for the 
Table 3 Exact protocol each subject received in each phase of the study

\begin{tabular}{|c|c|c|c|c|c|c|}
\hline \multirow[t]{2}{*}{ Subject } & \multirow[t]{2}{*}{ Species } & \multirow{2}{*}{$\begin{array}{l}\text { Familiarization } \\
\# \text { of sessions }\end{array}$} & \multicolumn{2}{|l|}{ Testing } & \multicolumn{2}{|l|}{ Control } \\
\hline & & & $\#$ of sessions ${ }^{\mathrm{a}}$ & Session \# & $\begin{array}{l}\text { Order of } \\
\text { controls }\end{array}$ & $\begin{array}{l}\text { \# of points } \\
\text { to cover }\end{array}$ \\
\hline Joey & Bonobo & 12 & 37 in 3 blocks (SB) & - & & \\
\hline Kuno & Bonobo & 2 & 26 in 3 blocks (BS) & Third & $\begin{array}{l}\text { H hides } \\
\text { Straw } \\
\text { H witness }\end{array}$ & $\begin{array}{l}3 / 5 \\
1 / 5 \\
1 / 6\end{array}$ \\
\hline Limbuko & Bonobo & 2 & 49 in 4 blocks (BS) & First & $\begin{array}{l}\mathrm{H} \text { witness } \\
\mathrm{H} \text { hides } \\
\text { Straw }\end{array}$ & $\begin{array}{l}1 / 5 \\
2 / 5 \\
2 / 5\end{array}$ \\
\hline Ulindi & Bonobo & 16 & 36 in 3 blocks (SB) & - & & \\
\hline Yasa & Bonobo & 3 & 31 in 3 blocks (SB) & First & $\begin{array}{l}\text { Straw } \\
\mathrm{H} \text { witness } \\
\mathrm{H} \text { hides }\end{array}$ & $\begin{array}{l}0 / 5 \\
5 / 5 \\
5 / 5\end{array}$ \\
\hline Dokana & Orang & 19 & 39 in 4 blocks (SB) & Second & $\begin{array}{l}\mathrm{H} \text { hides } \\
\text { Straw } \\
\text { H witness }\end{array}$ & $\begin{array}{l}1 / 5 \\
0 / 5 \\
2 / 5\end{array}$ \\
\hline Dunja & Orang & 13 & 51 in 5 blocks (BS) & Fifth & - & \\
\hline Padana & Orang & 14 & 44 in 4 blocks (BS) & First & $\begin{array}{l}\text { Straw } \\
\mathrm{H} \text { witness } \\
\mathrm{H} \text { hides }\end{array}$ & $\begin{array}{l}0 / 5 \\
2 / 5 \\
1 / 5\end{array}$ \\
\hline Pini & Orang & 13 & 38 in 4 blocks (SB) & First & $\begin{array}{l}\mathrm{H} \text { witness } \\
\mathrm{H} \text { hides } \\
\text { Straw }\end{array}$ & $\begin{array}{l}2 / 6 \\
1 / 5 \\
1 / 5\end{array}$ \\
\hline Toba (pilot) & Orang & 1 (fixed) & $\begin{array}{l}46 \text { in } 3 \text { blocks } \\
\quad(10 \times \mathrm{B}, 24 \times \mathrm{S}, 12 \times \mathrm{B})\end{array}$ & Second & $\begin{array}{l}\mathrm{H} \text { hides } \\
\text { Straw } \\
\mathrm{H} \text { witness }\end{array}$ & $\begin{array}{l}4 / 8 \\
0 / 5 \\
1 / 5\end{array}$ \\
\hline Walter (pilot) & Orang & 2 (fixed) & $\begin{array}{l}42 \text { in } 2 \text { blocks } \\
\quad(31 \times \mathrm{S}, 11 \times \mathrm{B})\end{array}$ & Tenth & $\begin{array}{l}\text { H hides } \\
\text { Straw } \\
\text { H witness }\end{array}$ & $\begin{array}{l}0 / 6 \\
0 / 5 \\
1 / 5\end{array}$ \\
\hline
\end{tabular}

Familiarization phase number of sessions each individual received, Testing phase number of sessions, number of Stranger/Baiter-blocks, order of hiders ( $S B$ Stranger-Baiter; BS Baiter-Stranger) and session in which each individual indicated a cover for the first time, Control phase order in which each individual received the controls (H hides Helper hides control, Straw Straw control, $H$ witness Helper witness control) and how often each individual pointed to a cover in a Control trial

${ }^{a}$ Order of blocks with different persons hiding the fork: $B S$ Baiter-Stranger, $S B$ Stranger-Baiter; the last block often contained less than 12 sessions

$\mathrm{b}$ The order of controls reflects the order in which the subject received the different types of controls (H hides Helper hides control, Straw Straw control, $H$ witness Helper witness control)

c Number of trials in which the subject pointed to a cover/total number of trials

fork in the tool box in Test trials. Although there were no overall significant differences in the mean frequency of these two strategies (Wilcoxon test: $z=1.13, N=9$, $P=0.26$; fork first: median $=38.5$, inter-quartile range $=28.6-51.9$; food first: median $=52.9$, inter-quartile range $=37.5-60.1$ ), a strategy switch took place over time. Figure 4 presents the percentage of Test trials in which subjects pointed to a cover before or after the helper had looked inside the tool box over the first 30 sessions. Subjects significantly increased their preference for pointing to a cover before the helper had looked for the fork $\left(r_{\mathrm{s}}=0.85\right.$, $P<0.001, n=30$ ) and decreased their preference for pointing to a cover after the helper had looked for the fork $\left(r_{\mathrm{s}}=-0.45, P=0.012, n=30\right)$.

\section{Control phase}

One orangutan (Dunja) did not reach the criterion to move on to the Control Phase and was therefore excluded from subsequent analyses. Figure 5 presents the percentage of trials in which the remaining eight subjects pointed first to a cover (irrespective of whether it was the actual hiding place of the fork) in the various trial types of the Control phase (15 Test trials, 5 trials of each Control type; for deviations see Table 3). There were significant differences between trial types (Friedman test: Chi-square $=11.87, d f=3$, $N=8, P=0.008$ ). Pairwise comparisons between the Test trials when compared to all Control trial types revealed that subjects pointed significantly more often in the Test trials 
(a) hiding locations

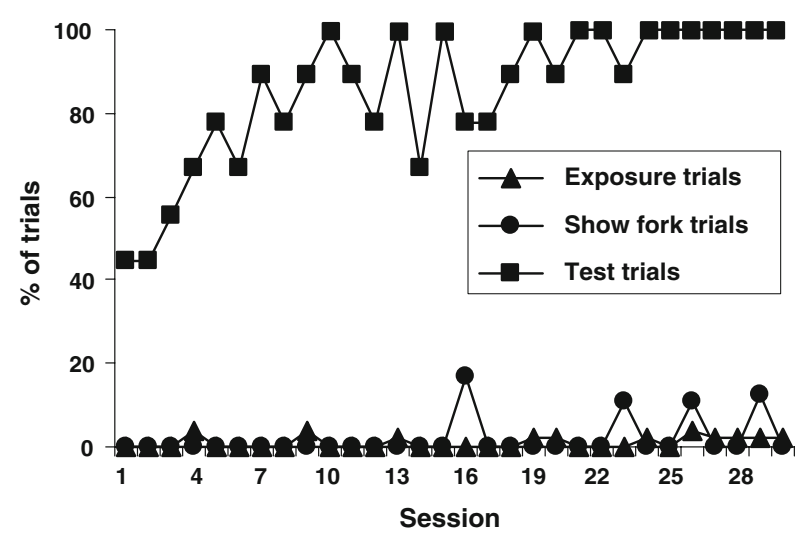

(b) tool box

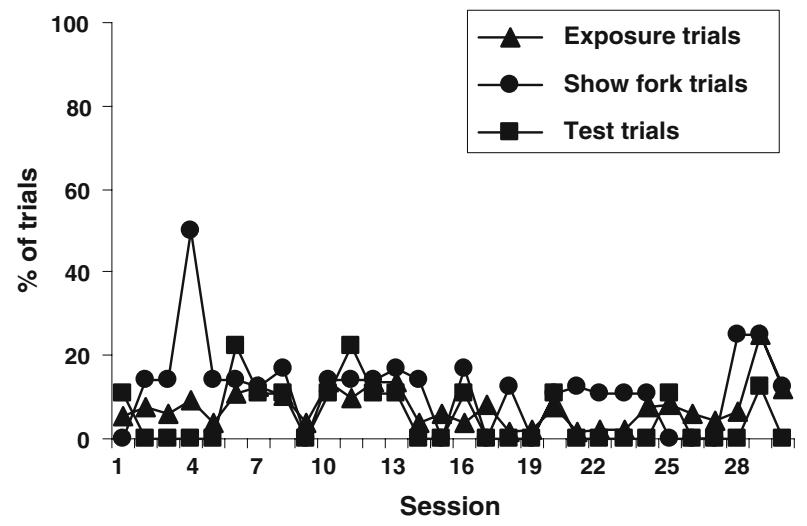

Fig. 2 Mean percentage of trials in which subjects pointed to the covers (a) and the tool box (b) during the first 30 sessions of the Testing phase as a function of condition $(N=9)$

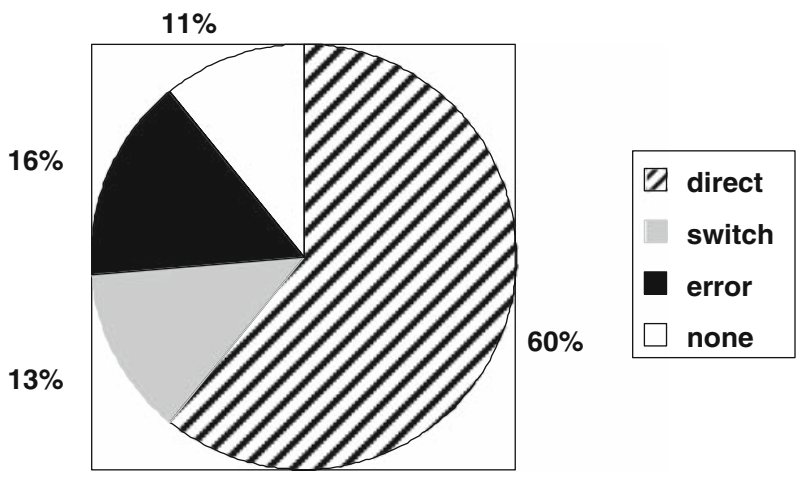

Fig. 3 Mean pointing accuracy to hiding place in Test trials $(N=9)$

than in the other trial types (Wilcoxon tests: Helper hides control: $z=1.99, \quad P=0.046$; Straw control: $z=2.37$, $P=0.018$; Helper witness control: $z=2.20, P=0.028$ ). The frequency of pointing first to the cover remained stable across the three blocks of trials for the Test (Friedman test: $\chi^{2}=0.30, d f=2, N=8, P=0.86$ ) and Control trials (Friedman test: $\left.\chi^{2}=1.46, d f=2, N=8, P=0.48\right)$ and the difference

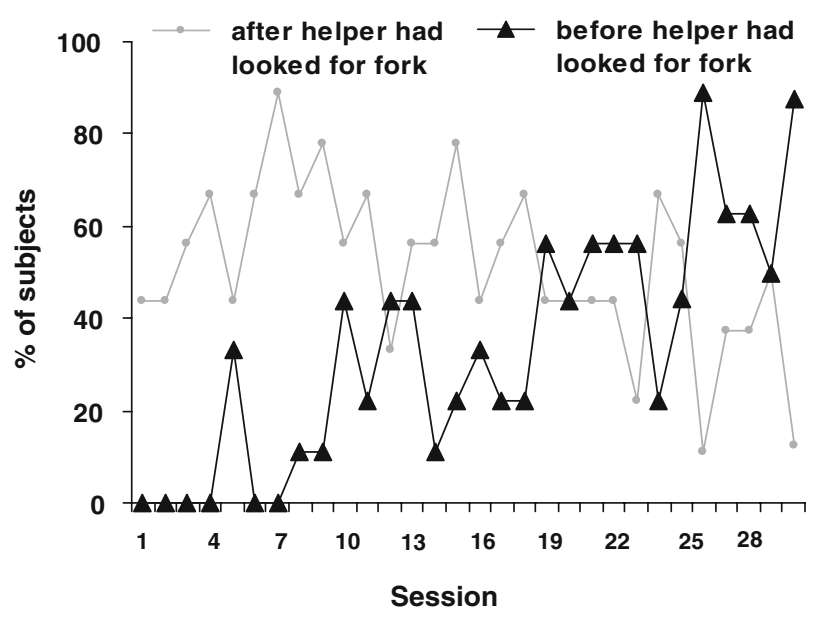

Fig. 4 Percent of subjects that pointed to the covers during the first 30 sessions of the Testing phase before or after the helper attempted to retrieve the fork from the (empty) tool box $(N=9)$

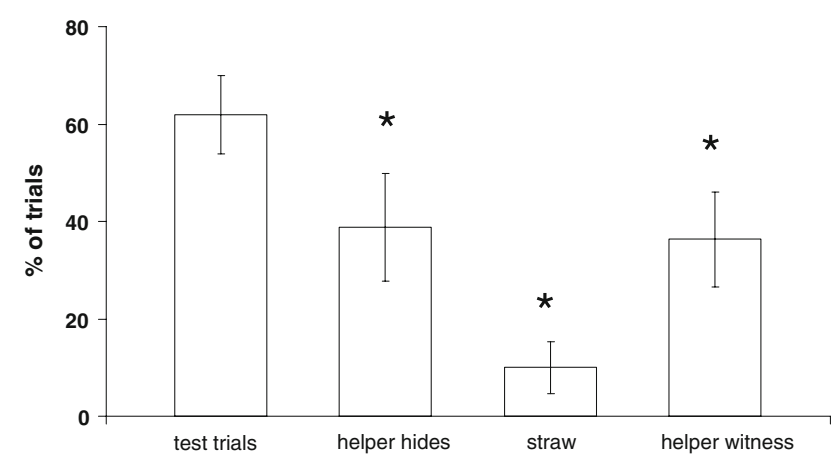

Fig. 5 Mean percentage of trials in which subjects pointed to the covers as a function of condition in the Control phase $(N=8)$. Asterisks indicate significant differences $(P<0.05)$ between Test trials and the different controls. Whiskers indicate the SEM

between Test and Control trials was already apparent in the first block of trials (Wilcoxon test: $z=2.38, P=0.017$ ). The two species did differ in one respect: the bonobos pointed significantly more to the covers than the orangutans in the Helper hides control (Mann-Whitney test: $Z=2.00$, $N=8, P=0.047$; Bonobos $(N=3)$ : median $=60$, interquartile range $=40-100$; Orangutans $(N=5)$ : median $=20$, inter-quartile range $=10-35$ ).

We also assessed whether the type of person hiding the fork (stranger vs. baiter) had an influence on the subjects' performance in the first block of sessions ( 10 sessions for Toba, 12 for all other subjects; $n=9$, Dunja included). Subjects who received Stranger trials first did not start to point to the covers in Test trials earlier (Mann-Whitney Test: $Z=0.13, N=9, P=0.090$; Stranger $(N=4)$ : median $=1.5$, inter-quartile range $=1-8$; Baiter $(N=5)$ : $\operatorname{median}=2$, inter-quartile range $=1-4$ ) nor did they point more to the covers in Test trials (Mann-Whitney test: $Z=0.74, N=9$, 
$P=0.46 ;$ Stranger: median $=75$, inter-quartile range $=30$ 90; Baiter: median $=83$, inter-quartile range $=61-96$ ). They also did not start pointing to the covers before the helper looked for the fork earlier (Mann-Whitney test: $Z=0.13, N=9, P=0.90$; Stranger: median $=10$, interquartile range $=6.25-12.25$; Baiter: median $=8$, inter-quartile range $=5-16$ ). Thus, subjects who experienced Stranger trials first did not perform better than subjects who experienced Baiter trials first.

\section{Discussion}

Orangutans and bonobos used pointing gestures to indicate hidden targets to people. The apes ${ }^{1}$ not only pointed consistently to hidden food to request it but also to a hidden fork that the human needed to retrieve the food for the ape. Although such flexible pointing has been previously documented in human-reared and enculturated apes (e.g., Call and Tomasello 1994; Gómez and Teixidor 1992; Kellogg and Kellogg 1933; Savage-Rumbaugh 1986; Whiten 2000), this study extends those findings to apes that have not been raised in a human-like environment. More specifically, in this study, six orangutans and three bonobos indicated the location of a fork that the human experimenter, but not the ape, was going to use. Pointing to the fork appeared spontaneously (the majority of the apes produced it from their first or second session) in conjunction to pointing to the desired goal (the baited tube) and was used more often in Test trials where the human did not know about the relocation of the fork. This suggests that apes understood the referential effect of their pointing gestures, i.e., that pointing has the power to selectively identify targets for others. Apes might learn to point in captivity by reaching towards the objects they want to get and learning that humans will give them to them. Our results show that their acquisition would in any case go beyond the function of acquiring items into a more referential use where the pointing action is no longer addressed to the ultimately desired item.

It is unclear, however, whether pointing was aimed at informing the human of the whereabouts of the fork (in the sense of making them know where the fork was), or it was aimed at directing them to the fork (Gómez 2004), i.e., some form of elaborate imperative where they are asking the human to retrieve the fork from its hiding and proceed to extract the food for them (Gómez 2004; Tomasello et al. 2007).

\footnotetext{
${ }^{1}$ As usual with ape studies, we found pronounced individual differences. Two of the apes (two bonobos) completely failed to point to the covers, and just pointed to the food. Also, our subjects did not always indicate the correct hiding place. In some instances, the apes would point to the wrong cover; usually correctly rectifying when the human failed to find the fork there.
}

Whatever the primary motive behind the pointing might be, the key question is, to what extent the apes understand that the human will not be able to find the fork without their help, i.e., to what extent the apes take into account the ignorance of the human when the hiding of the fork occurs in her absence. Human communication is modulated by a principle of "relevance" (Sperber and Wilson 1986). We tell or point out to others what we think that they have to know, i.e., we inform them of relevant things. The apes' pointing was functionally relevant. First, they selectively directed people to the fork's location (as opposed to distractor targets) when the fork's position had been changed, but not when it was in its usual position or it was handled by the baiter, but then placed back in its usual place (Show fork trials). In Exposure trials, apes typically pointed to the food location only. In contrast, in Test trials they pointed to the food and to the relocated fork. Crucially, the probability of pointing to the fork was significantly higher when it was hidden in the absence of the helper, than when it was hidden by the helper herself (at least in the case of the orangutans) or by another person but in the presence of the helper. Apes adapted their pointing to the information that was available or unavailable to the addressee: in the Test trials they pointed out to the human agent a new referent (the fork) that in Exposure trials was taken for granted. They could have pointed to both the food and fork in all the situations; however they significantly pointed to the fork when its whereabouts had changed, especially when this had happened in the absence of the helper. This mimics the relevance property of human communication.

It has been argued that in humans, relevance is achieved using theory of mind or mind-reading skills, which allow us to compute what others know, expect or ignore, and adapt our messages accordingly. Did the apes in our study achieve relevance by means of mind-reading skills, such as attributing knowledge and ignorance? An analysis across sessions shows that initially pointing to the fork occurred in response to the wrong searching behavior of the human, i.e., after the human had went to retrieve the fork from its usual place and did not find it. Anticipation that the human needs to be directed to the hiding place of the fork without behavioral signs of ignorance appeared only progressively, eventually becoming the dominant strategy. This is similar to what Gómez and Teixidor reported with their orangutan, Dona, who initially pointed to the hidden key only in response to the wrong search behavior by the human. However, Dona's shift in strategy occurred abruptly, coinciding with the introduction of a complete stranger as hider, whereas in the present study the shift was more gradual. Although the fork first strategy was suddenly adopted by some subjects, invariably they reverted to the food first strategy at some point throughout testing thus resulting in a gradual change, especially when the data from all individuals was considered together. 
However, apes pointed to the location of the fork on numerous occasions even when it was not needed because the helper knew the whereabouts of the fork. Consequently, this can be interpreted as evidence that apes did not possess human-like full-blown mind-reading skills. How can we reconcile these two findings? One possibility is that apes may go some way towards developing a simple version of what Tomasello et al. (2007) call sharing a "common conceptual ground" or a "joint attentional frame", in the sense of sharing contexts that are "known together"-an ability that has been attributed to human infants as early as at 12 months of age (Tomasello et al. 2007). There is recent evidence suggesting that human infants may be specifically adapted and motivated to do this sort of thing from very early (Liebal et al. 2008; Moll and Tomasello 2007; Tomasello and Haberl 2003) and in more complex ways, but apes may show here an evolutionary precursor of this (for example what Gómez (2008) calls the ability to code relations of "intentional availability" between agents and targets).

Our findings are consistent with reports suggesting that other apes (chimpanzees) can use some form of "knowledge versus ignorance" attribution in competitive contexts (Bräuer et al. 2007; Hare et al. 2001; Melis et al. 2006), but extend them to other species of apes and to a interspecific cooperative communicative context. Gómez's (2004) suggestion that introducing a competitive element (fork hidden by strangers) would improve performance was not supported by our results. Ape performance was similar whether the fork was hidden by known people or strangers. However, the special conditions of the Leipzig center (where apes are used to the regular presence of new people in the testing compartments) may have invalidated this manipulation (in contrast with Gómez and Teixidor's study, where the compartment in which the stranger appeared was strictly limited to keepers and the people in the experimenter team). The possibility that competitive factors facilitate performance in apes other than chimpanzees remains, therefore, an open question for future research.

In sum, bonobos and orangutans were capable of tailoring their communication in knowledge/ignorance scenarios. They repaired the inability of an agent to act upon a target by indicating the location of the target using an explicit referential signal (pointing). They did so initially in response to behavioral signs of inability, but went on to anticipate when this was needed, spontaneously discriminating among superficially similar situations. Although pointing was here part of a cooperative task, the ultimate beneficiaries of the cooperative actions were the apes. It remains to be determined if apes can point for purely altruistic purposes (cooperation where they are not the beneficiaries of the information transmission), as human infants do from around 12 months of age (Liszkowski et al. 2006), for example showing to humans the whereabouts of an object that is of use only to the human (a behavior Liszkowski et al. 2006 considered the true hallmark of "informative pointing").

Acknowledgments This work was supported by the EU project "Origins of referential Communication" (REFCOM-FP6-NESTPATH/CONTRACT 012787). We thank the Wolfgang Köhler Primate Center animal caretakers for their help in collecting the data. We thank Birte Hey, Alenka Hribar, Katja Grosse, Cécile Jammers, Natacha Mendes and all the "strangers" for the help in our tests. We thank two anonymous reviewers for their constructive and valuable comments that led to a much better paper. The reported experiments comply with all laws in Germany regarding animals' experiments.

Open Access This article is distributed under the terms of the Creative Commons Attribution Noncommercial License which permits any noncommercial use, distribution, and reproduction in any medium, provided the original author(s) and source are credited.

\section{References}

Bräuer J, Call J, Tomasello M (2007) Chimpanzees really know what others can see in a competitive situation. Anim Cogn 10:439448

Call J, Tomasello M (1994) Production and comprehension of referential pointing by orangutans (Pongo pygmaeus). J Comp Psychol 108:303-317

Call J, Tomasello M (1996) The effect of humans on the cognitive development of apes. In: Russon A, Bard KA, Parker ST (eds) Reaching into thought: the minds of the great apes. Cambridge University Press, Cambridge, pp 371-403

Cosmides L (1989) The logic of exchange: has natural selection shaped how humans reason? Studies with the Wason selection task. Cognition 31:187-276

Gómez JC (1996) Ostensive behavior in great apes: the role of eye contact. In: Russon AE, Bard KA, Parker ST (eds) Reaching in to thought: the minds of the great apes. Cambridge University Press, Cambridge, pp 131-151

Gómez JC (1998) Assessing theory of mind with nonverbal procedures: problems with training methods and an alternative "key" procedure. Behav Brain Sci 21:119-120

Gómez JC (2004) Apes, monkeys, children, and the growth of the mind. Harvard University Press, Cambridge

Gómez JC (2008) The evolution of pretence: from intentional availability to intentional non-existence. Mind Lang 23:586-606

Gómez JC, Teixidor P (1992) Theory of mind in an orangutan: a nonverbal test of false-belief appreciation. Paper presented at the XIV Congress of the International Primatological Society, Strasbourg, France

Goodall J (1986) The Chimpanzees of Gombe: patterns of behavior. Harvard University Press, Cambridge, MA, USA

Hare B, Tomasello M (2004) Chimpanzees are more skilful in competitive than in cooperative cognitive tasks. Anim Behav 68:571581

Hare B, Call J, Agnetta B, Tomasello M (2000) Chimpanzees know what conspecifics do and do not see. Anim Behav 59:771-786

Hare B, Call J, Tomasello M (2001) Do chimpanzees know what conspecifics know? Anim Behav 61:139-151

Hare B, Call J, Tomasello M (2006) Chimpanzees deceive a human by hiding. Cognition 101:495-514

Inoue-Nakamura N, Matsuzawa T (1997) Development of stone tool use by wild chimpanzees (Pan troglodytes). J Comp Psychol 111:159-173 
Kaminski J, Call J, Tomasello M (2004) Body orientation and face orientation: two factors controlling apes' begging behavior from humans. Anim Cogn 7:216-223

Kellogg WN, Kellogg LA (1933) The Ape and the child: a study of early environmental influence upon early behavior. McGraw-Hill, New York

Leavens DA, Hopkins WD (1998) Intentional communication by chimpanzees: a cross-sectional study of the use of referential gestures. Dev Psychol 34:813-822

Leavens DA, Hopkins WD, Bard KA (1996) Indexical and referential pointing in chimpanzees (Pan troglodytes). J Comp Psychol 110:346-353

Leavens DA, Hopkins WD, Thomas RK (2004) Referential communication by chimpanzees (Pan troglodytes). J Comp Psychol 118:48-57

Liebal K, Behne T, Carpenter M, Tomasello M (2008) Infants use shared experience to interpret pointing gestures. Dev Sci (in press)

Liszkowski U, Carpenter M, Striano T, Tomasello M (2006) Twelveand 18-month-olds point to provide information to others. J Cogn Dev 7:173-187

Melis A, Call J, Tomasello M (2006) Chimpanzees conceal visual and auditory information from others. J Comp Psychol 120:154-162

Menzel EW (1973) Leadership and communication in young chimpanzees. In: Menzel EW (ed) Precultural primate behavior. Karger, Basel, pp 192-225

Menzel CR (1999) Unprompted recall and reporting of hidden objects by a chimpanzee (Pan troglodytes) after extended delays. J Comp Psychol 113:426-434

Miles HL (1990) The cognitive foundations for reference in a signing orangutan. In: Parker ST, Gibson KR (eds) "Language" and intelligence in monkeys and apes: comparative developmental perspectives. Cambridge University Press, Cambridge, pp 511-539

Moll H, Tomasello M (2007) How 14- and 18-month-olds know what others have experienced. Dev Psychol 43:309-317
Núñez M, Rivière A (2007) Una reevaluación del Paradigma de la Creencia Falsa. Infancia y Aprendizaje 30:289-308

Patterson F (1978) Linguistic capabilities of a lowland gorilla. In: Peng $\mathrm{F}$ (ed) Sign language and language acquisition in man and ape. Westview Press, Boulder, CO, USA, pp 161-201

Russell JL, Braccini S, Buehler N, Kachin MJ, Schapiro S, Hopkins WD (2005) Chimpanzee (Pan troglodytes) intentional communication is not contingent upon food. Anim Cogn 8:263-272

Savage-Rumbaugh ES (1986) Ape language: from conditioned response to symbol. Columbia University Press, New York

Savage-Rumbaugh ES, McDonald K, Sevcik RA, Hopkins WD, Rubert E (1986) Spontaneous symbol acquisition and communicative use by pygmy chimpanzees (Pan paniscus). J Exp Psychol Gen 115:211-235

Sperber D, Wilson D (1986) Relevance: communication and cognition. Harvard University Press, Cambridge, MA, USA

Tomasello M, Haberl K (2003) Understanding attention: 12- and 18month-olds know what's new for other persons. Dev Psychol 39:906-912

Tomasello M, Carpenter M, Liszkowski U (2007) A new look at infant pointing. Child Dev 78:705-722

Veà JJ, Sabater-Pi J (1998) Spontaneous pointing behaviour in the wild pygmy chimpanzee (Pan paniscus). Folia Primatol 69:289-290

Virányi Z, Topál J, Miklósi Á, Csányi V (2006) A nonverbal test of knowledge attribution: a comparative study on dogs and children. Anim Cogn 9:13-26

de Waal F, van Hooff J (1981) Side directed communication and agonistic interactions in chimpanzees. Behaviour 77:164-198

Whiten A (2000) Chimpanzee cognition and the question of mental rerepresentation. In: Sperber D (ed) Metarepresentation: a multidisciplinary perspective. Oxford University Press, Oxford, pp 139167

Woodruff G, Premack D (1979) Intentional communication in the chimpanzee: the development of deception. Cognition 7:333-362 